\title{
ESTUDO DAS CONDIÇÕES SANITÁRIAS DAS ÃGUAS DE PISCINAS PÚBLICAS E PARTICULARES, NA CIDADE DE ARARAQUARA, SP, BRASIL
}

Clara Pechmann Mendonça*

Suzana Debora Ruff *

\begin{tabular}{l|l|} 
RSPUB9/401 \\
\hline
\end{tabular}

Mendonça, C. P. \& RuFf, S. D. Estudo das condições sanitárias das águas de piscinas públicas e particulares, na Cidade de Araraquara, SP, Brasil. Rev. Saúde públ., S. Paulo, 12:113-21, 1978.

RESUmo: Levando-se em consideraçâo que a natação é um exercicio excelente para a saúde e tem sido $u m$ esporte preferido por pessoas de várias idades de ambos os sexos; e que a massa liquida, contida em tanques, pode veicular doenças, procurou-se estudar as condiçóes sanitárias de algumas piscinas públicas $e$ particulares da Cidade de Araraquara, $S P$ (Brasil). Em 36 tomadas de amostras de águas de piscinas públicas e 22 de piscinas particulares, constatouse que, embora recebendo tratamento especifico, elas não mantêm os niveis de cloro suficiente para impedir a proliferação de bactérias, algumas das quais perigosas para a saúde dos freqüentadores. Verificou-se que os niveis de cloretos estavam altos, indicando contaminação das águas por urina ou mesmo suor do corpo, e concluiu-se que o banhista deveria receber instruçōes a respeito.

UnITERmos: Piscinas. Agua, análise.

\section{N T RODU Ç A O}

A natação é um exercício importante e tem sido recomendado no mundo inteiro sendo um dos esportes preferidos por pessoas de várias idades de ambos os sexos, principalmente em regiões como a nossa, onde o verão se prolonga por vários meses e é bastante intenso.

A heterogeneidade de idade e sexo num meio líquido pode, em parte, ser responsável pela disseminação de doenças transmissiveis, pois a superfície corpórea de contato é grande.

Existem alguns autores, e entre eles
Moore', que julgam mínimas ou mesmo inexistentes as possibilidades de veiculação de doenças dentro das piscinas, mesmo quando suas águas estejam consideravelmente poluídas.

Para 0 Sub-Committee on Water Quality Criteria 12, as atividades com prolongado e íntimo contato com a água envolvem considerável perigo de ingestão do líquido em quantidade suficiente a representar um significante risco para a saúde.

E comum a ocorrência de conjuntivite infecciosa, inflamação do orofaringe, afec-

* Da Faculdade de Ciências Farmacêuticas de Araraquara da UNESP. Rua Expedicionários do Brasil, 1621 - 14800 - Araraquara, SP - Brasil. 
MENDONÇA, C. P. \& RUFF, S. D. Estudo das condições sanitárias das águas de piscinas públicas e particulares, na Cidade de Araraquara, SP, Brasil. Rev. Saúde públ., S. Paulo. $12: 113-21,1978$.

ções de pele, síndromes disentéricos e outras, entre usuários de piscinas, havendo inclusive citação de surtos epidêmicos. Em 1938, Robertson 11 estudara quatro casos de Doença de Weil associado ao uso de piscinas; Miller ${ }^{8}$ relata prurido de nadadores causado por cercárias de Schistosoma. Em 1939, Taylor ${ }^{1 \pm}$ descreveu uma série de casos de otites e sinusites; Harry ${ }^{4}$, em 1940, encontrou também freqüentes casos de otites entre nadadores. Em estudos realizados na Suécia, em 1952 e 1954, Linell e Norden 6,7 relatam uma epidemia por bactéria álcool ácido resistente produzindo lesões cutâneas, semelhante às provocadas pelo $M$. tuberculosis, a qual denominaram de "moléstia das piscinas".

Embora essas ocorrências não sejam tão raras. tem sido dificil o relato desses problemas, pois sabemos que isso envolve não apenas o banhista, mas clubes e propprietários de piscinas particulares (Zingano ${ }^{15}$ ).

Vários fatores intervêm na ocorrência de doenças adquiridas nas piscinas, tais como: presença de microrganismos colonizados no corpo dos banhistas; poluição da água, do piso e dos objetos de uso dos freqüentadores; - diminuição da resistência orgânica do indivíduo pela fadiga provocada por exercícios, em intensidade, às vezes inconvenientes.

Parece que o maior problema consiste na contaminação da massa líquida por microrganismos provindos da mucosa nasal e da bucal, da região anal e perianal, da superfície corporal e da urina tão comumente lançada no meio líquido. Porém, se a água receber os devidos cuidados e se houver residuo de cloro em niveis adequados, haverá pouca possibilidade de sobrevivência dos contaminantes.

A finalidade deste trabalho foi verificar as condições sanitárias das águas em diferentes piscinas públicas e particulares de Araraquara, em dias de maior fluência de banhistas.

\section{MATERIAL E MẼTODOS}

Coletamos 36 vezes amostras de água de piscinas públicas denominadas A e B e 22 vezes amostras de piscinas particulares denominadas $\mathrm{C}$, durante os meses de outubro a dezembro de 1974,1975 e 1976. Todas as piscinas examinadas eram equipadas com sistemas de recirculação e tratamento de água.

Levamos em consideração a forma de tratamento, o número e tipo de freqüentadores e a hora da coleta das águas.

\section{a - Forma de tratamento}

Estudamos piscinas tratadas com HTH (Granularry clorite) ou super cloro e pelo sistema clássico usando-se a cọagulação, filtração e cloração com hipoclorito de sódio (cloro líquido);

\section{b - Número e tipo de freqüentadores}

O número de freqüentadores em relação ao tamanho do tanque foi sempre maior do que o permitido ${ }^{3,10}$ e as piscinas destinadas às crianças eram freqüentadas por grande número de adultos.

Os freqüentadores de piscinas públicas, assim como os das particulares eram, de diferentes sexos, idades e condições sócioeconômicas diversificadas.

\section{c - Hora da coleta das águas}

Procuramos coletar amostras no mesmo dia de todas as piscinas, escolhendo sempre o horário de maior fluência de freqüentadores. Planejamos coletar amostras seguidamente, mas, devido a influências climáticas, tivemos que, por vezes, contornar as dificuldades nos aproximando o mais possivel do desejado.

Para se estudar as condições das águas, realizamos coleta de material e semeadura.

\section{a - Coleta de material}

Para os exames microbiológicos, foram usados frascos com rolhas esmerilhadas, 
MENDONCA, C. P. \& RUFF, S. D. Estudo das condições sanitárias das águas de pıscinas públicas e particulares, na Cidade de Araraquara, SP, Brasil, Rer. Saúde públ., S. Paulo, $12: 113-21,1978$.

estéreis, contendo $0,1 \mathrm{ml}$ de tiosulfato de sódio a $10 \%$ para cada $100 \mathrm{ml}$ de água, a fim de reduzir o cloro. A coleta foi em três frascos e em três pontos diferentes da piscina, numa profundidade de, pelo menos, $30 \mathrm{~cm}$.

Para os exames parasitológicos, foran usados frascos estéreis de $500 \mathrm{ml}$, coletando-se amostras em dois pontos diferentes do tanque.

Para os exames químicos foram usados frascos de 1 litro, limpos e secos, sendo o material igualmente coletado em dois pontos diferentes do tanque. Este mesmo material foi utilizado para a verificação da turbidez e $\mathrm{pH}$;

\section{b - Semeaduras}

Para a verificação do "número mais provável", utilizamos três séries de cinco tubos usando os volumes de $10,0,1,0$ e $0,1 \mathrm{ml}$ de água em caldo lactosado e as estimativas foram obtidas diretamente pelas tabelas de Hoskins 5

Para a contagem padrão por $1 \mathrm{ml}$, plantamos $1,0 \mathrm{ml}$ e $0,1 \mathrm{ml}$ de água em "pour plate" em placas com $15,0 \mathrm{ml}$ de Nutrient ágar.

Para o isolamento de microrganismos, centrifugamos $100 \mathrm{ml}$ de cada amostra, a 3000 rotaçōes por minuto durante $15 \mathrm{~min}$., em condiçōes adequadas para evitar contaminaçāo. $O$ sedimento foi plantado de acordo com a orientação recebida de Russumano* por ocasião da realização do Curso sobre Tratamento de Ảguas, em 1973, em Sảo Paulo. Utilizamos os esquemas I, II, III, IV, V, de acordo com Current Practices in Water Microbiology ${ }^{1}$, com ligeiras adaptações. Os fungos foram estudados através do isolamento em microcultura em meio de Sabouraud glicose e meio de Mycosel.

ESQUEMA I

PESQUISA DE COLIFORMES

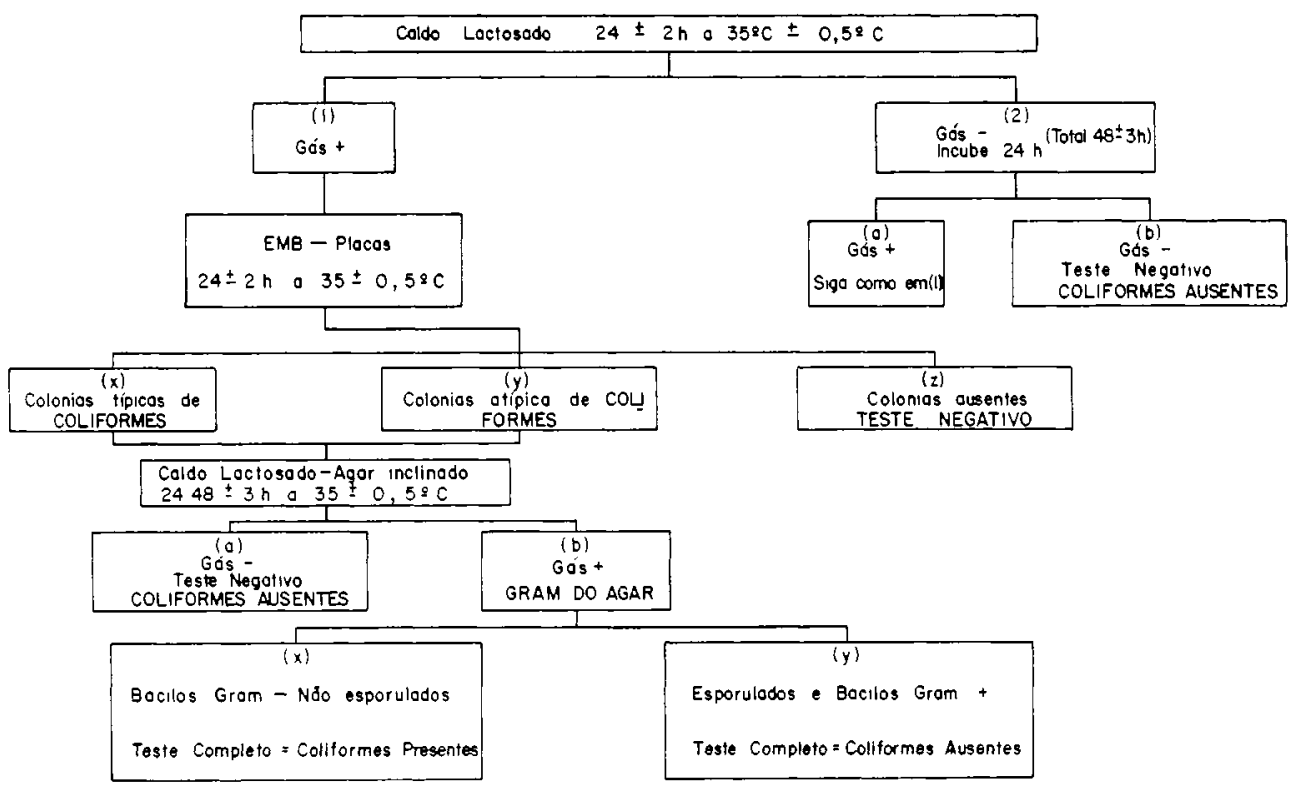

* Dr, Roceo Russumano. Microbiologista do National Training Center. Cincinati - USA 
MENDONÇA, C. P. \& RUFF, S. D. Estudo das condições sanitárias das águas de piscinas públicas e particulares, na Cidade de Araraquara, SP, Brasil. Rev. Saúde públ., S. Paulo. $12: 113-21,1978$

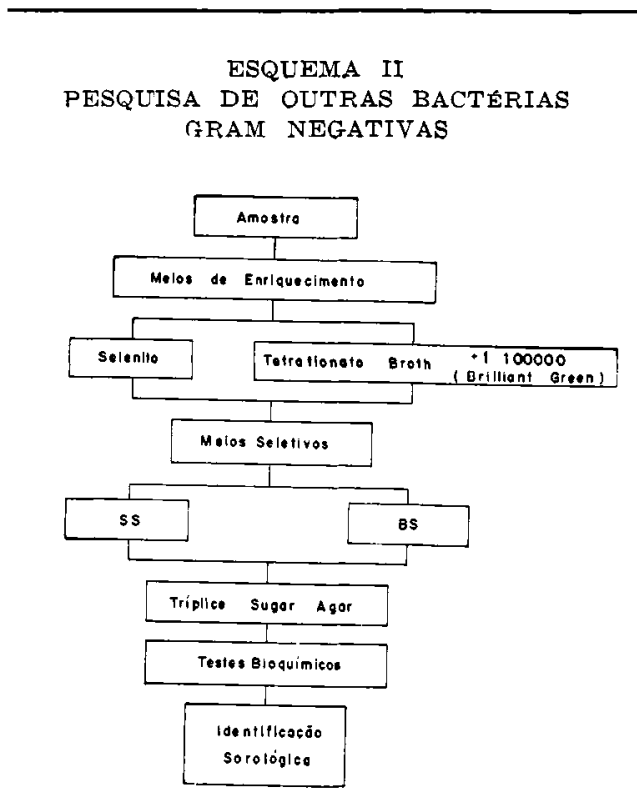

Para a pesquisa de helmintos e protozoários, centrifugamos igualmente um mínimo de $100 \mathrm{ml}$ de cada amostra a 3.000 rotações por minuto durante $15 \mathrm{~min}$. A dosagem dos cloretos foi feita pela técnica de Mohr e a do cloro pelo método "Standards". Para turbidez usou-se o método comparativo visual e o pH foi determinado pelo método colorimétrico com solução de indicadores correspondentes a cores "Standards" (Salvo ${ }^{13}$ ).

\section{RESULTADOS}

As Tabelas 1 e 2 apresentanı os resultados separadamente das piscinas públicas $A$ e $B$ e das particulares $C$, constituindo a média aritmética dos resultodos obtidos durante as três etapas de observação. Consideramos, assim, porque as resultados foram bastante aproximados.

ESQUEMA III

PESQUISA DE ESTREPTOCOCOS FECAIS

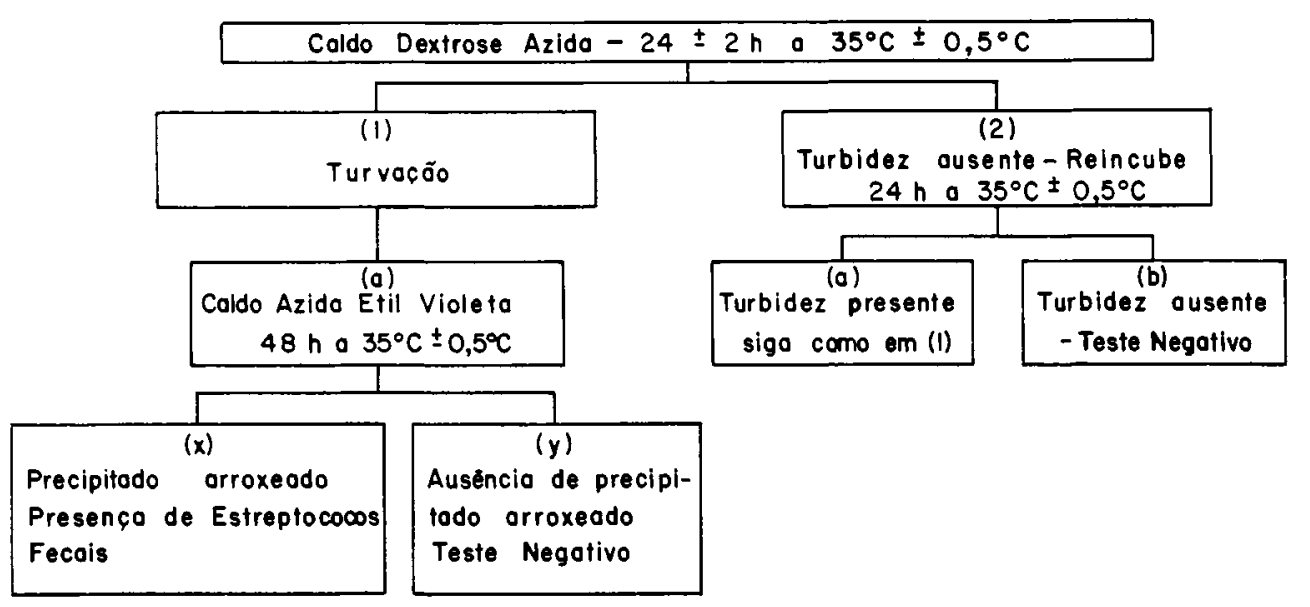




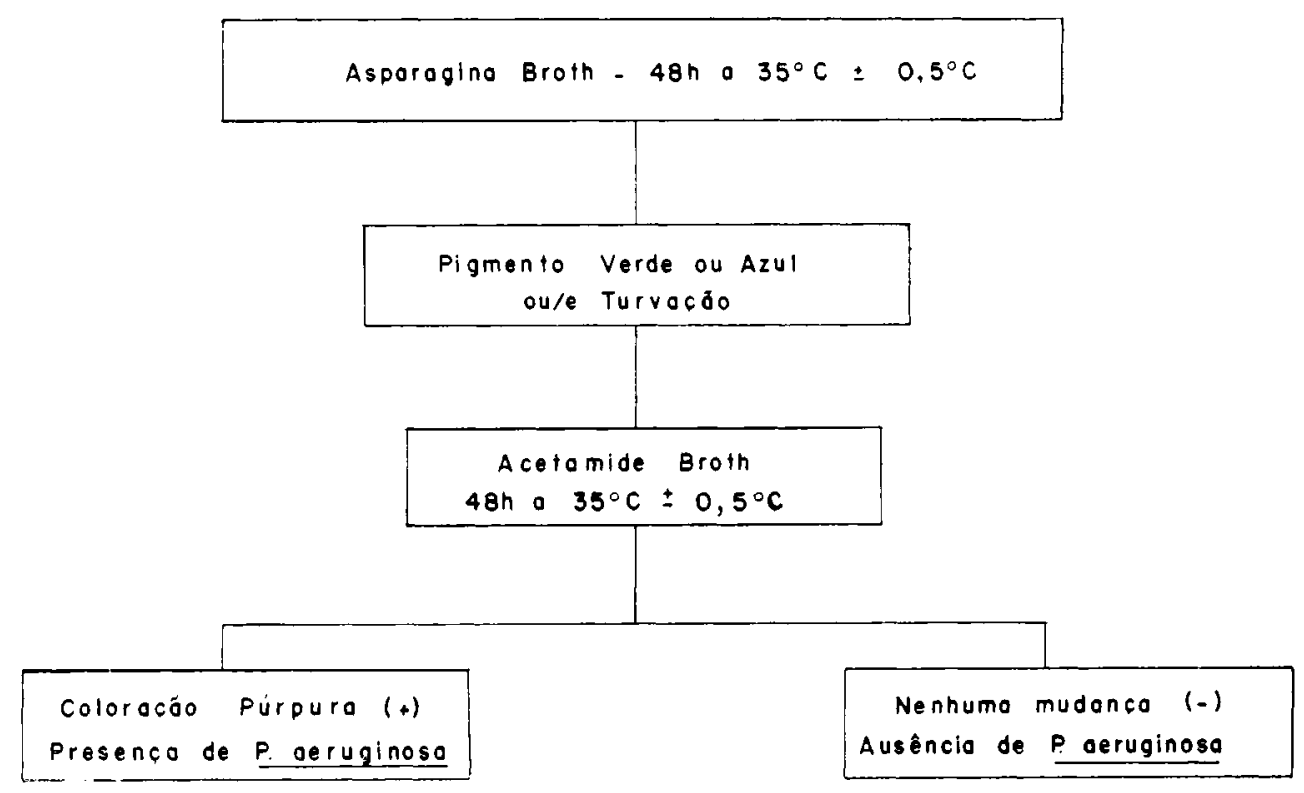

ESQUEMA V

PESQUISA DE STAPHYLOCOCCUS AUREUS

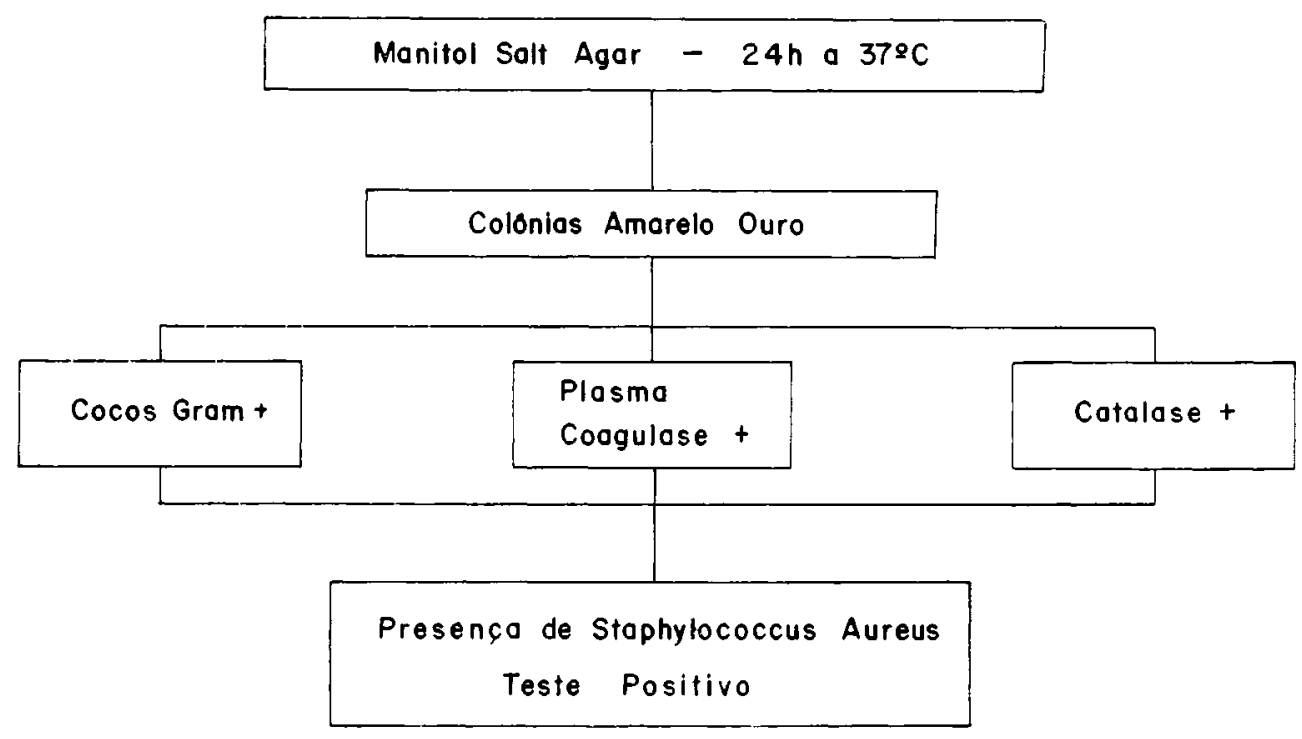

Fonte: Environmental Protection Agency, Water Programs operations. Curent practices in water microbiology. Cincinati. 197: 
MENDONÇA, C. P. \& RUFF, S. D. Estudo das condiçōes sanitárias das águas de piscinas públicas e particulares, na Cidade de Araraquara, SP, Brasil. Rev. Saúde públ., S. Paulo, $12: 113-21,1978$.

Dentre os fungos, isolamos Aspergillus $s p$., Rhodotorulla sp., e Neurospora.

Dentre as bactérias, isolamos na piscina $A$, nas duas primeiras etapas de observação, raríssimas colônias de Shigella flexnerii e Escherichia coli. Em uma piscina particular isolamos, além da Escherichia coli, freqüentes colônias de Klebsiella pneumoniae. Nas águas de lavapés, especialmente de piscinas públicas, isolamos, em todas as etapas, grande quantidade de fungos, colônias de Klebsiella pneumoniae e Escherichia coli. Em todas as piscinas foram sempre isoladas colônias de Staphylococcus aureus.

\section{DISCUSSAO}

Pelos resultados obtidos, as condições sanitárias das águas de piscinas examinadas, em Araraquara, no momento de maior fluência de banhistas, não foram consideradas boas, pois demonstraram contaminação por bactérias que podem pôr em risco a saúde dos usuários.

O encontro de Shigella flexnerii demonstra que as águas sofreram contaminação fecal. Inclusive isso foi reforçado pelo encontro de Escherichia coli e Streptococcus faecalis.
Embora tivéssemos submetido à reação, com soro aglutinante polivalente, todas as bactérias que demonstraram propriedades bioquimicas da Escherichia coli, não isolamos bactérias do grupo GEl. A presença de Staphylococcus aureus sugere contaminação das águas por germes colonizados na pele ou em cavidades naturais dos banhistas ou, talvez mesmo, em infecções várias.

A concentração de cloro residual foi bastante baixa principalmente quando houve grande número de banhistas. Houve ocasiões em que o cloro residual esteve a zero, tanto nas piscinas públicas, como nas particulares.

$\mathrm{O} \mathrm{pH}$ de todas as águas das piscinas examinadas nunca apresentou a faixa ideal $(7,2$ a 8,0$)$ e a turbidez foi sempre maior naquelas que possuiam área gramada próxima, especialmente sem lavapés.

A dosagem dos cloretos foi bastante elevada em todas as águas, tudo indicando contaminação por urina e suor do corpo humano.

Os lavapés, que deveriam ser colocados de tal maneira que os frequientadores não pudessem adentrar no tanque, sem passar por eles, mereceriam cuidados maiores. Verificamos, igualmente, que as normas adotadas pelos clubes não são realmente

T A B E L A 1

Média dos resultados dos exames físicos e químicos das águas de algumas piscinas públicas e particulares de Araraquara, SP, 1974 - 1976.

\begin{tabular}{c|c|c|c|c}
\hline & $\begin{array}{c}\text { Purbidez } \\
\mathrm{mg} / 0\end{array}$ & $\mathrm{pH}$ & $\begin{array}{c}\text { Cloretos } \\
\mathrm{mg} / 00\end{array}$ & $\begin{array}{c}\text { Cloro } \\
\text { mg/00 }\end{array}$ \\
\hline Piscinas & 2.5 & 5,0 & 61,46 & 0,02 \\
$\mathrm{~A}^{*}$ & 1.4 & 5,6 & 58,02 & 0.08 \\
$\mathrm{C}^{* *}$ & 1.1 & 5,5 & 40,62 & 0,20 \\
\hline
\end{tabular}

* Piscinas públicas

** Piscinas particulares 
MENDONÇA, C. P. \& RUFF, S. D. Estudo das condições sanitárias das águas de piscinas públicas e particulares, na Cidade de Araraquara, SP, Brasil. Rev. Saúde pübl., S. Paulo, $12: 113-21,1978$.

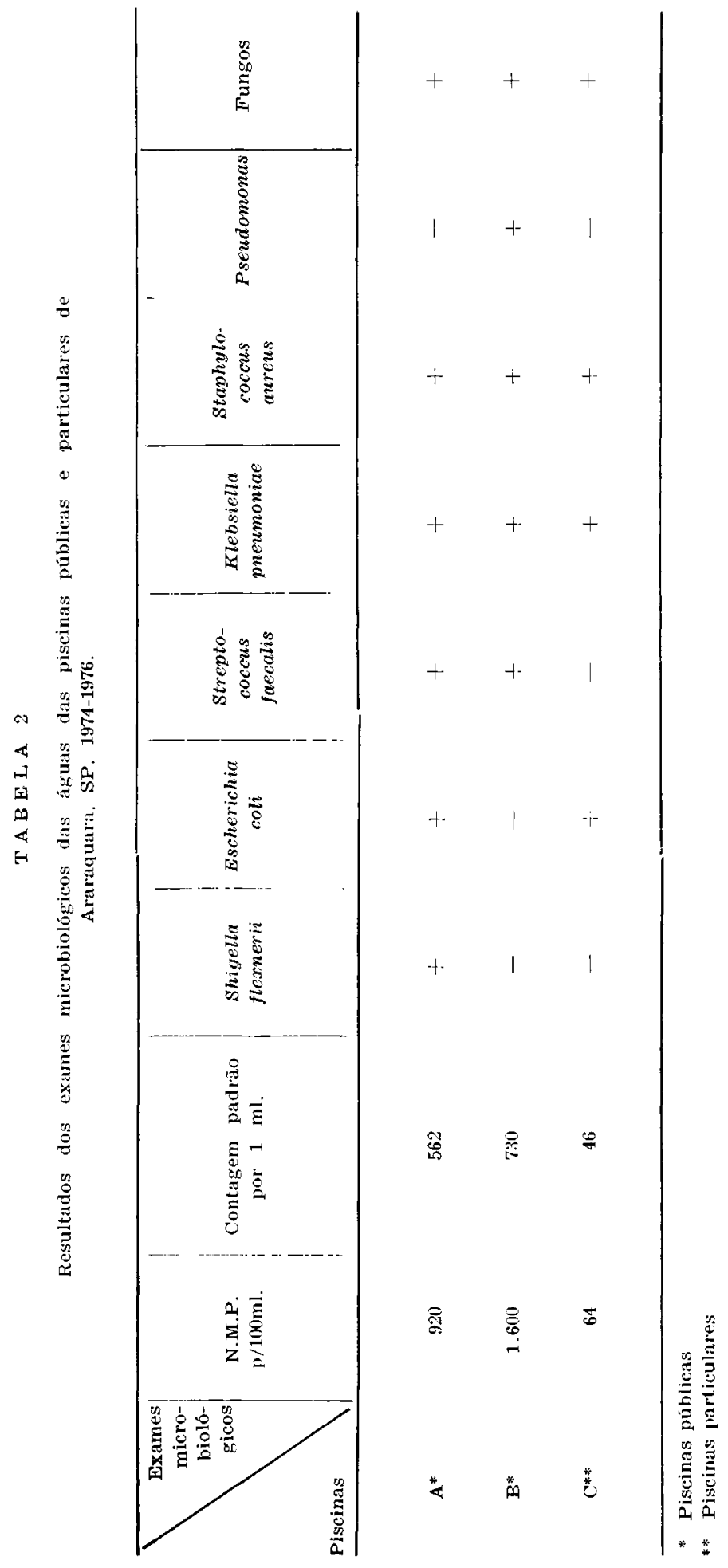


MENDONÇA, C. P. \& RUFF, S. D. Estudo das condições saritárias das águas de piscinas públicas e particulares, na Cidade de Araraquara, SP, Brasil. Rev. Saúde públ., S. Paulo, $12: 113-21,1978$.

seguidas pelos usuários. Nas piscinas, principalmente particulares, não há respeito da passagem obrigatória pela ducha antes de adentrar à água. As piscinas particulares parecem estar se transformando em mini-piscinas. Portanto, para resguardo da saúde, os usuários deveriam ser submetidos a um exame médico rigoroso e periódico.

Para Forattini 2, os riscos são tantus, sugerindo máximo rigor na realização dos exames médicos periódicos entre us frequentadores. Esses exames deverian constar de anamnese completa, exame clínico com inspeção das genitais e cavidades naturais, além de abreugrafia, e exames laboratoriais de fezes e secreção quando necessários.

Devemos esclarecer que não observamos diferença no grau de contaminação entre águas de piscinas com diferentes tipos de tratamentos. Sabemos que o HTH facilita bastante o serviço do operador, porém não ofereceu, em nossa observação, índice mais elevado de cloro residual nos momentos de grande fluência de banhistas.

\section{CONCLUSOES P SUGESTÖES}

- O encontro de Sh. flexnerii, E. coli e St. faecalis, embora em número reduzido, indica poluição fecal, representando perigo potencial à saúde.

- A presença constante do $S$. aureuls representa igualmente um perigo para a saúde dos usuários.

- A quantidade de cloro residual e o $\mathrm{pH}$, principalmente das águas das piscinas públicas, estiveram sempre abaixo do recomendado.
- A elevação da taxa de cloretos sugere contaminação das águas por urina e suor do corpo.

- Pouca, uu, às vezes, nenhuma fiscalização se observou obrigando a todos à prática dos requisitos de higiene.

- Sentimus que há necessidade de dar mais ênfase à profilaxia, orientando 0 banhista com as normas de educaçāo sanitária.

- O exame médico deveria ser mais rigoroso.

- As piscinas públicas, e mesmo as particulares, deveriam ser projetadas, construidas e operadas para funcionar com obediência a regulamentos, fazendo com que realmente fossem usadas como elemento necessário à saúde, recreação e ao equilibrio psicofisiológico.

Isso poderia ser conseguido se houvesse colaboração satisfatória do médico responsável, além dos banhistas e dos dirigentes ou proprietários das piscinas particulares. Acreditamos também que o útil funcionamento de uma piscina repousa essencialmente no trinômio:

"Cuntrole médico profilático exigente: Educação do banhista; Tratamento e conservação eficiente das águas". (Zingano, ${ }^{\text {ño }}$ ).

\section{AGRADECIMENTOS}

Aus farmacêuticos Mariza Landgraf e Paulo Roberto Natalino, ao Dr. Jorge Cury e aos Presidentes de Clubes e proprietários de piscinas particulares de Araraquara. 
MENDONÇA, C. P. \& RUFF, S. D. Estudo das condições sanitảias das águas de piscinas públicas e particulares, na Cidade de Araraquara, SP, Brasil. Rev, Saúde públ, S. Paulo, $12: 113-21.1978$.

RSPUB $9 / 401$

MENDoçA, C. P. \& RuFF, S. D. /Sanitary conditions of private and public swimming-pools in Araraquara, State of $S$. Paulo, Brazill Rev. Saúde públ., $S$. Pallo, 12:113-21, 1978.

ABSTRACT: Taking into account that swimming is excelent exercise for health in general, and has been prefered as a sport by people of all ages and both sexes, and that the liquid mass contained in tanks can transmit diseases. a study was undertaken in order to verify the hygienic conditions of some of the public and private swimming pools in the City of Araraquara, State of $S$. Paulo, Brazil. Thirty-six samples of water from public swimming pools and 22 from private ones were taken. It was verified that, although receiving a specific treatment, they did not maintain sufficient chlorine levels to restrain the proliferation of bacteria, some of which dangerous to the health of bathers. Likewise, chloride levels were seen to be high, which indicate that the water was contaminated by urine or even by sweat, leading to the conclusion that bathers must receive adequate instruction.

UnITERMS: Swimming pools. Water, analysis.

\section{REFERENCIAS BIBLIOGRÁFICAS}

1. ENVIRONMENTAL PROTECTION AGENCY. Water Programs Operations. Current practices in water microbiology. Cincinnati, 1973.

2. FORATTINI, O. P. apud LimA, C. S. Consideraçōes de ordem sanitária re. ferentes às principais piscinas existentes em Santa Maria, Rio Grande do Sul. Rev. Fac. Farm. Bioq. Santa Maria, 15(1):13-24, 1969.

3. GUANABARA. Leis e Decretos, etc. Regula. mentos de piscinas do Estado do Guanabara; decreto E. no 5499, Rio de Janeiro, 1973.

4. HARRY, P. A. Swimmer's otites, Prescriber, 34:125-6, 1940.

5. HOSKINS, J. K. Most probable number's for evaluation of coliaerogenes tests by fermentation tube method. Publ. Hlth Rep, 49:393-405, 1934.

6. LINELL, F. \& NORDEN. A. Skin infections from swimming pools due to new type of Mycobacterium. Nord, Med., 47 : 888-91, 1952.

7. LINELL, F. \& NORDEN, A. Mycobacterium balnei: new acidfast bacillus occuring in swimming pools and capable of producing skin lesions in humans. Acta tuberc, scand., (Suppl. 33) :1-84, 1954 .

8. MILLER, M. J. \& MUNROE, E. Schistosomose dermatitis in Quebec. Canad. med. Ass. J., 65:571-5. 1951.
9. MOORE, E. W. Water and its relations to diseases. In: Sartwell, P. E. ed Maxcy-Rosenau preventive medicine and public health. 9th ed. New York, Appleton-Century-Crofts. 1965. p. 954-60.

10. PUPO, A. S. Protecão das piscinas. Curitiba, Univ. Fed. Paraná, 1965.

11. ROBERTSON, K. M. Four cases of weil: disease infected from same stream. Brit. med. J., 2:1300-4, 1938.

12. RUSSOMANNO, R. Water quality criteria for recreation and aesthetics. In: Environmental Protection Agency. Water Programs Operations. Training Program. Current practices in water Microbiology. Cincinnati, 1973. p. 6.16.6 .

13. SALVo, $\mathrm{S}$. de. Tratamento de agua para fins urbanos e industriais. São Paulo, Escola Técnica "Oswaldo Cruz", 1964.

14. TAYLOR, H. M. Otites and sinusitis in swimmer, with enphasis on man's lack of adaptation to acquatic environment. J. Amer. med. Ass., 113:891-4, 1939.

15. ZINGANO, A. G. Contribuição ao estudo higiênico das piscinas de Porto Alegre. Porto Alegre, 1956. [Tese de Doutoramento - Faculdade de Medicina].

Recebido para publicação em 04/04/197y. Aprovado para publicasão em 14/07/197\%. 